\title{
Biological and Social Determinants of Responsiveness to Infants in 10-to-15-Year-Old Girls ${ }^{1}$
}

\author{
Ann M. Frodi ${ }^{2}$ \\ University of Rochester \\ Ann D. Murray \\ Boys Town, Omaha \\ Michael E. Lamb \\ University of Utah \\ Jamie Steinberg \\ University of Michigan
}

Subjects filled out questionnaires and were individually observed interacting with an 8-to-12-month-old infant in a waiting room. Hidden observers recorded the frequency of ignoring, responsiveness to infant bids, and of social bids to the infant. Analyses revealed that older girls ignored more, made fewer bids, and responded less than younger girls did. However, chronological age was highly correlated with measures of biological and social maturity. Multiple regression analyses were used to determine which of these factors best predicted the developmental decline in baby responsiveness. Multiple regressions showed that social maturity was the best predictor of the number of bids to the infant, followed by the development of secondary sex characteristics and menarcheal status ( $\mathrm{R}=.44)$. Social maturity, babysitting experience, and menarcheal status were the significant predictors of ignoring $(\mathrm{R}=.48)$, while menarcheal status,

\footnotetext{
${ }^{1}$ This research was supported by grants from the Riksbankens Jubileumsfond and the Humanistisk-Samhällsvetenskapliga Forskiningsradet of Sweden to Ann M. Frodi. The authors are grateful to Sharon Bienstock for her assistance.

${ }^{2}$ Correspondence should be sent to Ann Frodi, Department of Psychology, University of Rochester, Rochester, New York 14627.
} 
development of secondary sex characteristics, and babysitting experience predicted responsiveness $(\mathrm{R}=.49)$. Possible reasons for the decreased interest in infants are discussed, as are the implications for research using baby responsiveness as a measure of sex-role-related changes in adolescence.

In the last few years, several researchers have investigated the emergence or strengthening of sex differences in early adolescence. Many of these investigators have used indices of interest in or responsiveness to infants as dependent measures, reasoning that it is sex appropriate for girls and sex inappropriate for boys to be interested in babies (see Berman, 1980, for a review). The present study was concerned with developmental changes in "baby responsiveness" among girls. Previously reported findings have been remarkably consistent. Fullard and Reiling (1976) reported a substantial increase between ages 12 and 14 years in girls' preferences for looking at pictures of babies, while the increases among boys were much smaller. Feldman, Nash, and Cutrona (1977) reported no sex differences in 8-to-9-year-olds, while 14-to-15-year-old girls preferred pictures of babies more than boys did. Focusing only on girls, Goldberg and Kriger (Note 1) confirmed an increase in girls' preferences for pictures of infants between 12 and 14 years. They also found that postmenarcheal girls preferred looking at pictures of infants more than premenarcheal girls of the same age did. Two studies of behavioral responsiveness to unfamiliar infants showed sex differences among 14-year-olds that did not exist in younger children (Feldman et al., 1977, Frodi \& Lamb, 1978). Both of these investigations employed a "waiting room" procedure in which the subjects were observed individually in the presence of a young infant and its mother. The authors of these studies likewise intimated that during early adolescence, girls become more interested in infants than they had been previously. The consistency of these conclusions despite differences in methodology is quite impressive: In her review, Berman (1980) reported poor intercorrelations among behavioral, picture preference, psychophysiological, and self-report measures of interest in infants.

Two explanations of the emergent sex differences, and especially of the increased interest in babies among girls, have been offered. Fullard and Reiling (1976) proposed that the hormonal changes of puberty feminize girls, strengthening an adaptive behavior for females of reproductive age. Although they set out to discount this hypothesis, Goldberg and Kriger (Note 1) concluded that their data also implicated biological determinants. By contrast, Feldman et al. (1977) and Frodi and Lamb (1978) have argued that the sex differences intensify because of increasing social pressures on adolescents to conform to cultural sex stereotypes. This argument is consistent with Nash and Feldman's (1982) evidence that sex differences wax and wane throughout the life span depending on changing role expectations and demands. However, no one has attempted to assess social and biological influences in the same study in order to compare their relative contribution to females' responsiveness to infants. The present study was designed to do this. We correlated behavioral measures of interest in 
infants with indices of biological and social maturity in a large sample of preand postpubescent girls. Although it is more tedious to collect data on behavioral measures than on picture preference measures, we chose to focus on the behavioral measures because they seemed to us to have greater face validity.

Like Feldman et al. (1977), Feldman and Nash (1978, 1979a, 1979b), and Frodi and Lamb (1978), we observed our subjects unobtrusively in a "waiting room." The waiting room procedure involves the unobtrusive observation of a subject in the presence of a mother and her infant. Behavioral responsiveness is assessed by observing the subject's interaction with the infant. To assess biological maturity, we asked the girls about their menarcheal status and development of secondary sex characteristics. The social variables assessed included an index of social maturity (comprising a number of activities - frequency of dating, shaving legs, using lipstick, dancing with boys -- which adolescent girls perceive as indices of social maturity) and measures of babysitting experience, gender-related personality traits, and attitudes toward women. We also used two measures of self-consciousness, since adolescents are known to be highly self-conscious (Elkind, 1980). We felt that both our waiting room procedure and several of our questions (e.g., the ones dealing with menarche and secondary sex characteristics) might elicit self-consciousness, especially in the older teenagers, and that this might affect their interaction with the infant.

\section{METHOD}

\section{Subjects}

Ninety-three girls ranging in age from 10 to 15 years ( $X=12.7$ years) participated in the study. Of the subjects, 4 were 10 years of age, 9 were 11,7 were 12, 35 were 13, 16 were 14, and 22 were 15. Scores on the Hollingshead (Note 2) Four Factor Index of Social Status indicated that most subjects came from middle-class families $(\bar{X}=53.0, S D=12.3)$. All of the subjects came from a small midwestern university town. Seventy-one (76\%) of the subjects' mothers were employed outside the home. Three of the participants had no siblings, 38 had one, 26 had two, 13 had three, and 13 had four or more. The subjects were recruited through newspaper advertisements, offering five dollars for participation in research involving less than an hour's work "filling out some questionnaires."

\section{Procedure}

There were two parts to the study: a questionnaire session and a waiting room session. Subjects were scheduled to come in pairs; one sat in the waiting room, while the other filled out questionnaires; then, the two changed places. 
The Questionnaire Session. During this session, a female researcher was present to assist the younger subjects in understanding and filling out the instruments. Subjects older than 12 needed little help. The subjects first completed a background questionnaire, on which they indicated their age, sibling status, and their parents' educations and occupations. A series of questions focused on the subjects' frequency, age of onset, and attitudes toward babysitting; responses to these yielded a composite measure of Experience with Babies (possible range, 0-6 points). Another series of questions concerned age of onset and frequency of dating (5-point scale), dancing with boys (5-point scale), wearing lipstick (5-point scale), and shaving legs (5-point scale). Scores on these items were summed to yield a composite measure of Social Maturity (possible range 4-20 points). Both the measures of Experience with Babies and Social Maturity were developed for use in this study. A final item on the questionnaire asked whether the subject had reached menarche and, if so, when she first menstruated. Of the 93 subjects, 47 had not reached menarche, 14 had reached menarche within the last year, and 32 had reached menarche more than a year earlier. For the 46 postmenarchea! subjects, mean age of menarche was 12.5 years $(S D=1.21$ years).

The development of secondary sex characteristics was assessed by the subjects, who were shown sketches (redrawn following Tanner, 1978) of the four stages of breast, nipple, and pubic hair development and asked to indicate which sketch was most like themselves. Scores of these three aspects were summed to yield a composite measure (possible range $3-12 ; \bar{X}=7.88, S D=2.6$ ). To avoid embarrassing the subjects, the researchers presented the sketches and then kept their distance from the subjects, who wrote down their own responses. Morris and Udry (1980) recently reported extremely high agreement between professionals' assessments and self-reports using these sketches.

The subjects also completed the Self-Consciousness Scale (Fenigstein, Scheier, \& Buss, 1975), the Attitudes toward Women Scale (Spence, Helmreich, \& Stapp, 1973), and the intermediate version of the Personal Attributes Questionnaire (Spence, Helmreich, \& Stapp, 1974) - a measure of gender-related personality traits. All of these instrumets have been demonstrated to have satisfactory psychometric properties, although the Self-Consciousness Scale has not to our knowledge been used before with 10-to-15-year-olds. Subjects also rated on a scale of 1 to 5 their agreement with the statement "I think a lot about how I appear to the opposite sex" ("self-consciousness with boys" scale).

The Waiting Room Session. The subjects individually waited their turn in a waiting room containing several age-appropriate magazines, plants, a bowl of goldfish, a table, several chairs, infant toys, and a mother-infant dyad, ostensibly waiting to take part in another study. Eleven babies ( 5 female) ranging from 8 to 12 months of age served as confederates. The infants were not restrained; all were able to (and did) move around the room quite extensively. 
Unbeknownst to the subjects, they were observed for 20 minutes from behind a one-way window from the time they sat down in the waiting room. Observers watched the subject and infant for 10 seconds and entered the data on a checklist for the next 5 seconds, yielding a total of 80 observation units. Observers noted whenever the subjects smiled, gestured, made faces, looked, vocalized, offered toys, touched, or were within three feet of the infant and whenever the infants looked, smiled, proferred toys, vocalized, touched, fussed, or cried. The subjects' interactions with the mothers were not considered. From the observational records, the following measures of the subjects' behavior were derived: Composite sociability (sum of all the subject's behaviors to the infant), Ignore (the proportion of infant bids to which the subject did not respond - even by looking - in the same time unit or the next), and Responsiveness (the proportion of infant bids to which the subject responded in the same time unit or the next with a behavior other than just looking). ${ }^{3}$ These variables were, of course, significantly intercorrelated. The correlation between composite sociability and ignore was -.61 ; between composite sociability and responsiveness, .72; and between responsiveness and ignore, - -65 .

Interobserver Reliability. Behavior in two-thirds of the waiting room sessions was recorded simultaneously by two observers. Product-moment correlations between the two observers' records indicated that the behavioral measures were reliably recorded; agreement was .94 for Composite Sociability, .92 for Ignore, and .90 for Responsiveness.

\section{RESULTS}

Preliminary analyses revealed no significant effects on any measure for sex of infant confederate or identity of infant confederate. There was, however, a significant order effect: Responsiveness was higher among subjects who were observed before completing the questionnaires $(\bar{X}=.30)$ than among subjects who completed questionnaires first $(\bar{X}=.16, F(1,91)=5.99, p<.02)$. There were no statistical interactions between order and any other factors. Analyses of the responsiveness data revealed similar findings, regardless of whether analyses were conducted involving data for all subjects, only for those who completed the questionnaires first, and only for those who completed the questionnaires last. Nevertheless, we controlled (by covariation) for order effects in all analyses of responsiveness reported below.

\footnotetext{
${ }^{3}$ In their research, Feldman and Nash (1978, 1979a, 1979b; Feldman et al., 1977) use "responsiveness" to refer to measures of the frequency of social bids to infants. Thus, their measure of responsiveness is similar to our Composite Sociability measure rather than to our measure of contingent responsiveness to infant bids.
} 


\section{Correlations with Chronological Age}

Contrary to expectations, age was negatively correlated with Composite Sociability $(r=-.26, p<.006)$ and with Responsiveness $(r=-.11, p<.15)$ and was positively correlated with ignoring $(r=.34, p<.0001)$. Interpretation of these findings was difficult, however, because age was predictably correlated with several of the background variables, including menarcheal status $(r=.63$, $p<.0001)$, development of secondary sex characteristics $(r=.66, p<.0001)$, social maturity $(r=.70, p<.0001)$, self-consciousnes with boys $(r=.34, p<$ $.0001)$, and babysitting experience $(r=23, p<.01)$. However, age was not significantly correlated with attitudes toward women, gender-related personality traits, or self-consciousness; and these three measures were also insignificantly related to the three measures of baby responsiveness. Consequently, these measures were not considered in further analyses.

\section{Determinants of Behavior in the Waiting Room}

Since age is of interest to developmental psychology only as a surrogate index of other events, our primary goal was to determine which developmental events accounted for the decline with age in baby responsiveness. Since previous researchers have identified puberty in their explanations, we first examined the relationship between menarcheal status and baby responsiveness. Compared with girls who had not yet reached menarche, girls who had menstruated scored significantly lower on the measure of composite sociability $(t(92)=2.31, p<$ $.05)$ and ignored infant bids significantly more often $(t(92)=3.01, p<.005)$. There was a nonsignificant tendency $(p<.15)$ for the postmenarcheal girls to be less responsive. Inspection of scatterplots relating menarcheal age to the behavioral measures unexpectedly suggested that there were substantial differences between girls who had recently (within the last year) reached menarche and those who reached menarche a year or more earlier. Post hoc analyses comparing three levels of menarcheal status (premenarcheal, recently menarcheal, postmenarcheal) revealed significant effects on all three measures of behavior toward the infant (Composite Sociability $F(2,86)=4.66, p<.012$; Ignore $F(2,86)=7.83, p<.001$; Responsiveness $F(2,86)=685, p<.002)$. Group means are presented in Table I, which also shows the results of group comparisons. In general, the recently menarcheal girls resembled premenarcheal subjects more than postmenarcheal subjects. Subjects who were premenarcheal or had reached menarche within the last year ignored less, responded more to the infant's bids, and made more social bids to the infant than the postmenarcheal subjects did.

On the Composite Sociability measure, the effect for menarcheal status was eliminated when social maturity, frequency of dating (a component of 


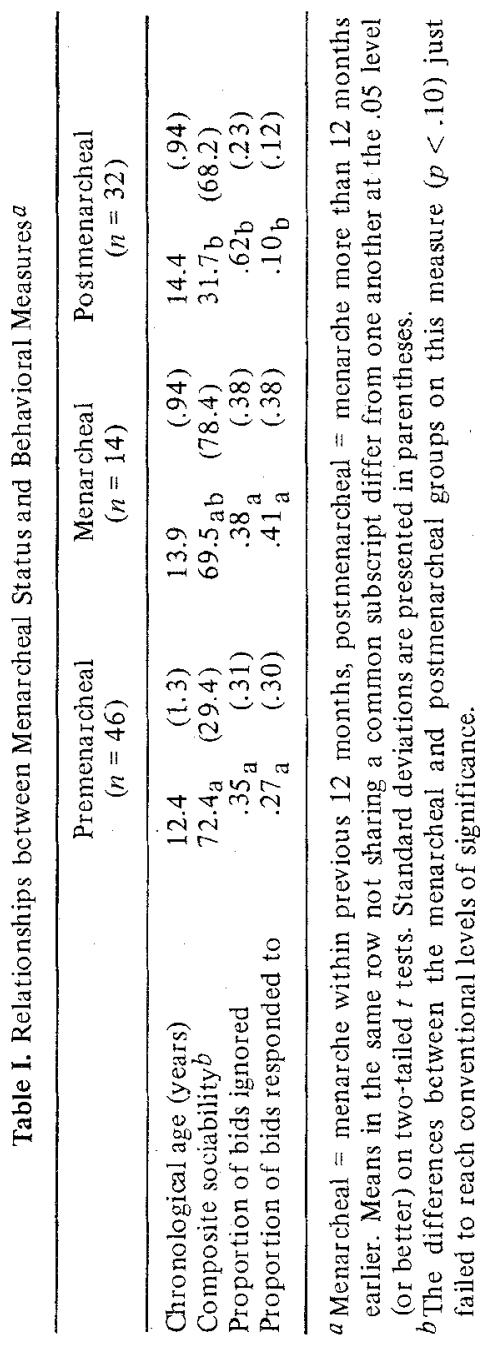


social maturity), or age was used as a convariate in ANCOVAS. ${ }^{4}$ When menarcheal status, development of secondary sex characteristics, social maturity, selfconsciousness with boys, babysitting experience, and chronological age were used as predictors of composite sociability in a stepwise multiple regression, the first variable to enter was social maturity $(F(1,87)=7.50, p<.01)$, followed by development of secondary sex characteristics $(F(1,87)=6.90, p<.03)$, and menarcheal status $(F(2,87)=5.53, p<.01)$. The more socially and biologically mature the subject, the fewer bids she made to the infant. None of the other variables contributed to the prediction equation, in which $19 \%$ of the variance was accounted for $(R=.44)$.

The effect for menarcheal status on the measure of ignoring remained significant even when the effects of age, social maturity, frequency of dating, or babysitting experience were separately controlled in ANCOVAS; but when age and any of these other variables were controlled simultaneously, the effect for menarcheal status became insignificant. In a stepwise multiple regression using the same variables as for Composite Sociability, the first variable to enter was social maturity $(F(1,87)=3.29, p<.05)$, followed by babysitting experience $(F(1,87)=3.43, p<.05)$, and menarcheal status $(F(2,87)=3.53$, $p<.05$ ). The reduced regression model with these three predictor variables accounted for $23 \%$ of the variance $(R=.48)$. Subjects who were socially and biologically mature and who had more babysitting experience were more likely to ignore the infant's bids.

However, the effects for menarcheal status on responsiveness remained significant when the covariates were employed singly or in combination. Stepwise multiple regressions confirmed the importance of menarcheal status in predicting responsiveness to the infant's bids; this was the first variable to enter $(F(2,87)=14.63, p<.01)$, followed by secondary sex characteristics $(F(1$, $87)=7.45, p<.01)$, and babysitting experience $(F(1,87)=5.38, p<.01)$. The reduced regression model accounted for $24 \%$ of the variance $(R=.49)$.

\section{DISCUSSION}

The data gathered in the present study show that girls' interest in interaction with infants declines maturationally between late childhood and adolescence. This developmental tendency was evident on all three of our behavioral measures. The measures of social maturity proved to be the best predictors of the trends on two of the three measures; biological maturation was the best predictor of the declines on the measure of responsiveness.

\footnotetext{
${ }^{4}$ Whenever the main effect for menarcheal status in our ANCOVAS was eliminated by covariation of one or more variables, we reanalyzed the data using the former covariate as the factor and menarcheal status as the covariate. In every case, the significant covariates were shown to have a significant relationship to the behavioral measures whichever way the analysis was performed.
} 
At first glance, these results appear to contradict the findings previously reported. In fact, they do not. Only after we had begun the study did we recognize that there was a major discrepancy between results previously obtained using measures of behavioral interest and those obtained using picture preference measures. Although sex differences on both types of measures increase in early adolescence, the age by sex interactions are very different. On behavioral measures, unlike picture preference measures, girls do not become more and boys less responsive to infants. Rather, both boys and girls become less interested in interacting with infants between 8-9 and 14-15 years of age, with the decrease among boys being greater than that among girls. Frodi and Lamb (1978) noted the finding briefly in their study, since it was not expected. Fullard and Reiling's (1976) hypothesis is that hormonal factors associated with puberty feminize girls and make them more interested in babies is not supported: if any thing, the hormonal changes are associated with a decline in girls' interest in interacting with infants. Since all but 3 of our subjects reported some maturation of secondary sex characteristics, we cannot claim to have studied girls whose hormonal feminization had not yet begun. However, we can assume that the 8to-9-year-olds studied by Frodi and Lamb (1978) had not yet begun their pubertal spurt (cf. Tanner, 1978) and also ignored the infants less than the postmenarcheal young adolescents with whom they were compared. Although the data clearly contradict Fullard and Reiling's (1976) hypothesis, there is no obvious explanation for the finding that biological maturation is associated with declining interest in infants.

We would like to suggest that baby responsiveness is not a good measure for exploring the strengthening of sex-role related sex differences in early adolescence. During early adolescence, individuals are interested in establishing heterosexual relationships, so that on measures of interest in boys (not infants), we should see developmental increases in girls. Paralleling these increases, there should occur developmental decreases in measures of sex-role-irrelevant behaviors (interest in infants, for example). Both of these trends were evident in the present study. Since interest in infants is sex-role irrelevant for adolescent boys and girls, behavioral measures of interest in infants are inappropriate measures for studying the waxing and waning of sex-role-related sex differences in childhood and adolescence.

As noted in our introduction; picture preference measures of interest in babies do show sharp increases among pubescent girls (Feldman et al., 1977; Fullard \& Reiling, 1976, Goldberg \& Kriger, Note 1). Our failure to find such developmental trends using behavioral measures of baby responsiveness adds further confirmation to Berman's (1980) conclusion that different measures of baby responsiveness generally yield very different findings. Like Berman, we see no obvious reason why behavioral and picture preference measures should yield such different developmental trends; perhaps adolescent girls feel that they should be interested in infants and so report that they are, even though unobtrusive observations belie their claims. It would have been interesting to 
observe the subjects alone with the infants, since the observers' impression was that the older girls were much more self-conscious in the mothers' presence than the younger girls were. Unfortunately, we had to give up our initial attempts to gather such data after persistent failures $(n=31)$ on the part of our infant collaborators to cooperate without distress.

Unexpectedly, we found that girls who had reached menarche recently resembled premenarcheal girls rather than those who had reached menarche more than a year earlier, even though they were closer in age to the latter girls. Interestingly, Goldberg and Kriger (Note 1) mention that interest in babies was highest in postmenarcheal seventh graders, a group which is likely to consist largely of recently menarcheal girls. This finding (if replicated) underscores the fact that puberty should be viewed as a continuum rather than as a single event. Certainly, we know from endocrinological data that hormonal changes continue after menarche, with adult levels being attained at least a year later (Faiman $\&$ Winter, 1974). In future studies of biological influences during adolescence, it would thus be valuable to consider multiple indices of biological maturation (e.g., the development of secondary sex characteristics), not just menarcheal status. Further research would also benefit from the inclusion of a comparison group of subjects who have not yet developed secondary sex characteristics.

\section{REFERENCES NOTES}

1. Goldberg, S., \& Kriger, A. Interest in infants in pre-and postmenarcheal girls: Evidence for biological influences. Paper presented to Sou theastern Conference on Human Development, Alexandria, V., April 1980.

2. Hollingshead, A. B. Four factor index of social status, 1965. Unpublished manuscript (available from the author, Department of Sociology, Yale Station, New Haven Conn. 06520.)

\section{REFERENCES}

Berman, P. W. Are women predisposed to parenting: Developmental and situational determinants of sex differences in responsiveness to the young. Psychological Bulletin, $1980,88,668-695$.

Llkind, D. Strategic interaction in early adolescence. In J. Adelson (Ed.), Handbook of adolescent psychology. New York: Wiley, 1980.

Faiman, C., \& Winter, J. Gonadotropins and sex hormone patterns in puberty. In M. Grumback, G. Grave, \& F. Mayer (Eds.), Control of the onset of puberty. New York: Wiley, 1974.

Feldman, S. S., \& Nash, S. C. Interest in babies during young adulthood. Child Development, 1978, 49, 617-622.

Feldman, S. S., \& Nash, S. C. Changes in responsiveness to babies during adolescence. Child Development, 1979, 50, 942-949. (a)

Feldman, S. S., \& Nash, S. C. Understanding sex differences in responsiveness to babies among mature adults. Developmental Psychology, 1979, 15, 430-435. (b)

Feldman, S. S.; Nash, S. C., \& Cutrona, C. The influence of age and sex on responsiveness to babies. Developmental Psycholo y, 1977, 13, 675-676. 
Fenigstein, A., Scheier, M. F., \& Buss, A. H. Public and private self-consciousness: Assessment and theory. Journal of Consulting and Clinical Psychology, 1975, 43, 522-527.

Frodi, A. M., \& Lamb, M. E. Sex differences in responsiveness to infants: A developmental study of psychophysiological and behavioral responses. Child Development, 1978, $49,1182-1188$.

Fullard, W., \& Reiling, A. M. An investigation of Lorenz' "babyness." Child Development, $1976,47,1191-1193$.

Morris, N. M., \&. Udry, J. R. Validation of a self-administered instrument to assess stage of adolescent development. Journal of Youth and Adolescence, 1980, 9, 271-280.

Nash, S. C., \& Feldman, S. S. Sex role and sex-related attributions: Constancy or change across the family life cycle? In M. E. Lamb \& A. L. Brown (Eds.), Advances in developmental psychology (Vo1. 1). Hillsdale, N.J.: Lawrence Erlbaum, 1982.

Spence, J. T., Helmreich, R. L., \& Stapp, J. A short version of the Attitudes toward Woman Scale (AWS). Bullet in of the Psychonomic Society. 1973, 2, 219-220.

Spence, J. T., Helmreich, R., \& Stapp, J. The Personal Attributes Questionnaire: A measure of sex-role stereotypes and masculinity-femininity. JSAS Catalog of Selected Documents in Psychology, 1974, 4, 43. (Ms. No. 617).

Tanner, J. Fetu into man. Ca mbridge, Mass. : Harvard University Press, 1978. 